\title{
VALIDATION OF PULMONARY SCORE IN THE EVALUATION OF ACUTE EXACERBATION OF ASTHMA
}

Chandrakala P1, A. C. Ramesh ${ }^{2}$, Chaitra Rao B ${ }^{3}$

\section{HOW TO CITE THIS ARTICLE:}

Chandrakala P, A. C. Ramesh, Chaitra Rao B. "Validation of Pulmonary Score in the Evaluation of Acute Exacerbation of Asthma". Journal of Evolution of Medical and Dental Sciences 2014; Vol. 3, Issue 10, March 10; Page: 2465-2469, DOI: 10.14260/jemds/2014/2159

ABSTRACT: BACKGROUND \& OBJECTIVES: Numerous asthma scoring systems have been devised which combine a number of physical signs to estimate the severity of an acute asthma exacerbation. Although more than 16 scoring systems exist, many are difficult to use. The pulmonary score was developed to provide "user-friendly" measure of asthma severity for children with acute asthma exacerbation. The objective of the study is to study the efficacy of pulmonary score in assessing the severity of acute exacerbation of asthma in comparison to peak expiratory flow rate. METHODS: The study sampled 50 children, aged 5-18 years, with mild to moderate acute exacerbation of asthma. The PEFR (best of three attempts) and the PS were measured before and after treatment at 5, 10 and 15 minutes. The PS includes respiratory rate, wheezing, and retractions, each rated on a 0-3 scale. Pre- and post-treatment PEFR and PS score were compared using paired t-tests to establish construct validity. Correlation of pre- and post-treatment PSs with PEFRs was measured to establish criterion validity. RESULTS: The mean predicted PEFR improved with treatment by $21.2 \%$ (from $50.8 \%$ to $72.0 \%$ of predicted) ( $\mathrm{p}<0.0001$ ) at 15 minutes. The mean PS improved by 2.8 (from 4.8 to 2) (p < 0.0001 ) at 15 minutes. Pre- and post-treatment PSs were significantly correlated with PEFRs. The correlation of pre-treatment PEFR and PS is $r=-0.497(\mathrm{p}=0.000)$, that for post treatment at 15 minutes is $r=-0.589(\mathrm{p}=0.000)$. INTERPRETATION \& CONCLUSION: These data support the construct and criterion validities of the PS as a measure of asthma severity among children. The PS is a practical substitute to estimate airway obstruction in children who are too young or too sick to obtain PEFRs.

KEYWORDS: Asthma; severity score; pediatric; validation; pulmonary score; PEFR.

INTRODUCTION: Bronchial asthma is undoubtedly one among the recurrent and chronic diseases of childhood. Accurate measurement of the severity of an acute asthma exacerbation is important to guide initial treatment and to monitor response to subsequent therapy. The most accurate method to measure severity is spirometry. ${ }^{1}$ Unfortunately, spirometry requires special equipment not often available in the emergency department, as well as staff trained to perform and interpret the results. In the emergency department the peak expiratory flow rate (PEFR) is often used to estimate the degree of airway obstruction in lieu of spirometry. However, spirometry and PEFR are difficult methods for younger children to perform, or children of any age with severe obstruction.2

A number of asthma severity measures or scoring systems have been established which combine a number of physical signs, such as respiratory rate and accessory muscle use, to form an aggregate score that estimates the severity of an acute asthma exacerbation. Although more than 16 severity scoring systems exist, many are difficult to use. ${ }^{3}$ For example, some severity measures require blood gas analyses; others require numerous objective measures, or demanding assessments 
such as inspiratory/expiratory ratios. ${ }^{4-7}$ The pulmonary score (PS) was developed to provide a "userfriendly" measure of asthma severity for children with an acute asthma exacerbation.

The purpose of this study is to validate the pulmonary score as a measure of airway obstruction in children presenting to the emergency department for treatment of an acute asthma exacerbation.

AIMS AND OBJECTIVES: To study the efficacy of pulmonary score in assessing the severity of acute exacerbation of asthma in comparison to peak expiratory flow rate.

MATERIALS AND METHODS: The study was conducted from December 2011 to June 2013 at the Department of Pediatrics, Kempegowda Institute of Medical Sciences Bangalore, after Institutional Ethical Committee clearance. It was a prospective comparative study in which 50 asthmatic children presenting with mild to moderate exacerbation of asthma in the age group of 5 to 18 years were selected after taking informed consent. Suspected or known immunosuppressive, cardiac and neurological condition affecting pulmonary function and other chronic pulmonary disease were excluded from the study. Prior to starting treatment, they were initially assessed by measuring peak expiratory flow rate and pulmonary score.

Pulmonary score is assessed by 3 variables -respiratory rate, wheezing, use of accessory muscle-each variable is awarded 4 scores-0, 1, 2, 3 summed up to 9.

\begin{tabular}{|c|c|l|l|}
\hline SCORE & $\begin{array}{c}\text { RESPIRATORY } \\
\text { RATE }\end{array}$ & \multicolumn{1}{|c|}{ WHEEZE } & \multicolumn{1}{|c|}{$\begin{array}{c}\text { USE OF ACCESSORY } \\
\text { MUSCLE }\end{array}$} \\
\hline 0 & $\leq 20$ & None & No retraction \\
\hline 1 & $21-35$ & $\begin{array}{l}\text { Terminal expiration With } \\
\text { stethoscope }\end{array}$ & $\begin{array}{l}\text { Intercostal/subcostal } \\
\text { retraction }\end{array}$ \\
\hline 2 & $36-50$ & $\begin{array}{l}\text { Entire expiration With } \\
\text { stethoscope }\end{array}$ & $\begin{array}{l}\text { Intercostal/subcostal } \\
\text { retraction + suprasternal } \\
\text { retraction }\end{array}$ \\
\hline 3 & $>50$ & $\begin{array}{l}\text { Both inspiration and expiration } \\
\text { with or without stethoscope }\end{array}$ & 2+ use of ala nasi \\
\hline \multicolumn{2}{|c|}{ TABLE 1: PULMONARY SCORE } \\
\hline
\end{tabular}

PEFR measured using mini Wright Peak Flow Meter EU Scale before starting treatment and best of the 3 readings considered. Observed PEFR was expressed as the percentage of normal PEFR which was taken based on height and sex. Treatment started according to standard protocol of asthma management. Patients reassessed about 5 minutes after first dose of bronchodilator therapy, then at 10 minutes, 15 minutes and for inpatients at the time of discharge by doing PEFR and pulmonary score.

STATISTICAL METHODS: Pearson correlation coefficient is used to find negative correlation coefficient between pulmonary score and peak expiratory flow rate before and after treatment. Paired t-test and Analysis of variance is used to measure the significant improvement in peak expiratory flow rate and pulmonary score after treatment. 
RESULTS: Fifty children were evaluated, ranging from 5 to 18 years of age, with a mean age of 9.7 years. PEFR and PS were evaluated before and after treatment at 5, 10 and 15 minutes for each patient. There was a significant change in PEFR and PS before and after treatment.

\begin{tabular}{|c|c|c|c|c|c|c|c|c|c|c|}
\hline & \multicolumn{5}{|c|}{ Peak expiratory flow rate } & \multicolumn{5}{|c|}{ Pulmonary score } \\
\hline & $\begin{array}{l}\text { Before } \\
\text { treatment }\end{array}$ & $\begin{array}{c}\text { At } \\
5 \\
\text { minutes }\end{array}$ & $\begin{array}{c}\text { At } \\
10 \\
\text { minutes }\end{array}$ & $\begin{array}{c}\text { At } \\
15 \\
\text { minutes }\end{array}$ & $\begin{array}{c}\text { At } \\
\text { discharge }\end{array}$ & $\begin{array}{c}\text { Before } \\
\text { treatment }\end{array}$ & $\begin{array}{c}\text { At } \\
5 \\
\text { minutes }\end{array}$ & $\begin{array}{c}\text { At } \\
10 \\
\text { minutes }\end{array}$ & $\begin{array}{c}\text { At } \\
15 \\
\text { minutes }\end{array}$ & $\begin{array}{c}\text { At } \\
\text { discharge }\end{array}$ \\
\hline Mean & 50.8 & 62.9 & 64.5 & 72 & 82.9 & 4.8 & 3.8 & 3.1 & 2 & 1.27027 \\
\hline SD & 2.2 & 3.8 & 3.6 & 2.4 & 6.04 & 0.7 & 0.6 & 0.6 & 0.6 & 0.450225 \\
\hline
\end{tabular}

TABLE 2: MEAN AND SD OF PEFR \& PS

The mean predicted PEFR improved with treatment by $21.25 \%$ from $50.8 \%$ to $72.0 \%$ of predicted ( $\mathrm{p}<0.0001)$ by 15 minutes. The mean PS improved by $2.8(\mathrm{p}<0.0001)$ from 4.8 to 2 by 15 minutes.

The PS had a significant negative correlation with the PEFR. The correlation of pre-treatment PEFR and PS is $r=-0.497(\mathrm{p}=0.000$, that for post treatment at 5 minutes is $\mathrm{r}=-0.599(\mathrm{p}=0.000)$, at 10 minutes is $r=-0.592(p=0.00007)$ and at 15 minutes is $r=-0.589(p=0.000)$.

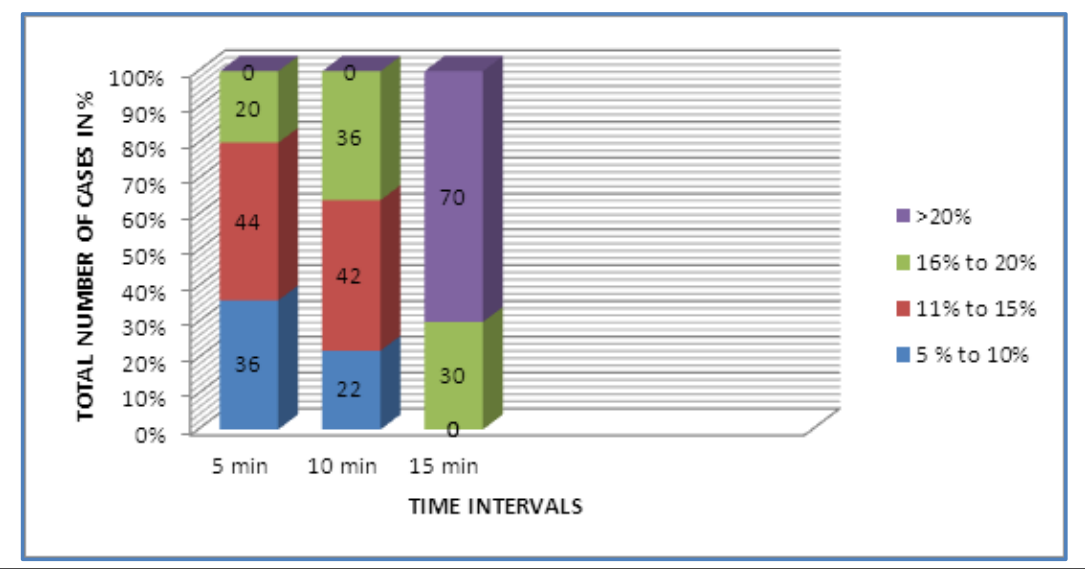

\section{FIGURE 1: PREDICTED IMPROVEMENT OF PEFR IN PERCENTAGE DISCUSSION}

- The PS passed two formal tests of validity i.e. construct and criterion validity.

- Construct validity in this study is the degree to which the PS measures airway obstruction. To establish construct validity, we compared the pre- and post-treatment PSs and the pre- to posttreatment PEFRs. The PEFR improved with treatment from a mean predicted PEFR of $50.2 \%$ to $72 \%(p=0.000)$. It is assumed that if the PEFR improves with treatment, the degree of airway obstruction decreases. The PS should reflect this change, indicated by a decrease in numerical score. The PS decreased with treatment from a mean of 4.8 to $2.0(p=0.000)$.

- The PEFR was used as the established criterion and both the PEFR and the PS were measured at the same time. The correlations between the pre-treatment PS and PEFR is $r=-0.497$. The posttreatment correlations is $r=-0.589$ at 15 minutes. The PEFR was chosen as the established criterion because it is often used to determine the severity of an asthma exacerbation. 
- Although pulmonary function tests (PFTs) may provide a better measure of airway obstruction, PFTs require special equipment and training for a staff to interpret. Both PEFRs and PFTs require cooperation from children to obtain accurate measures of airway obstruction. The PS is a simple objective method to assess the severity of an acute asthma exacerbation in children.

- In this study, correlations between the PSs and PEFRs ranged from -0.497 to -0.589 and are similar to the correlations found when other clinical scoring systems have been compared with estimates of lung function or signs of respiratory distress. The clinical severity score (CSS) was compared with arterial oxygen saturation and FEV1, with correlations of $r=0.49$ and $r=0.52$, respectively ${ }^{8}$. The asthma severity score (ASS) correlated with oxygen saturation $(r=-0.45)$ and FEV1 $(r=-0.54)^{9}$. These correlations may seem lower than what is expected; however, all of these scoring systems are based on physical signs (components) that do not actually measure airway obstruction. So when compared with measures of actual airway obstruction, there is limited correlation.

- Furthermore, when the clinical appearance of a child with asthma improves with treatment, the underlying obstruction may not improve to normal for several weeks. This makes comparing measures of airway obstruction with clinical scores difficult. The delayed improvement of airway obstruction helps explain why some children in this study had PSs suggestive of mild severity but had lower than expected PEFRs.

- Children with significant respiratory distress are likely to have difficulty performing PEFRs because they cannot inhale completely before exhaling forcefully. One reason the PS correlated better with the PEFR after bronchodilator therapy may be that the child's ability to perform PEFRs improved with lessening airway obstruction.

\section{LIMITATIONS:}

- The PS was compared with the PEFR, which is a substitute for spirometry.

- Only older children who could perform PEFRs were included.

- Since not all patients were inpatients and there was no uniformity in treatment after first dose of bronchodilator, PEFR and PS could not be compared at the time of discharge.

- Application of the PS to a younger group, and those with more severe presentations, may be avenues of further research.

CONCLUSION: The PS is a convenient simple method of assessing airway obstruction. The PS appears to correlate better with lesser airway obstruction than greater airway obstruction; i.e. the PS has higher post-treatment correlations, which makes the PS a good tool to assess mild severity and the response to treatment. No scoring system is perfect, but some method of assessing severity in children is needed when spirometry testing is not obtainable. The PS appears to be an objective and simple scoring system for the assessment of airway obstruction for children. The PS has been validated by two standard tests of validity. Construct validity of the PS through correlation of the preand post-treatment scores and criterion validity by correlation between the PS and the PEFR were established. Therefore, the PS can be used to assess airway obstruction in children who are unable to perform other measures, such as PEFRs, and may be used to guide therapy and to evaluate a child's response to treatment. 


\section{REFERENCES:}

1. Papadopoulos N G et al. European journal of allergy and clinical immunology: International consensus on paediatric asthma, 30 May 2012.

2. Gorelick MH, Stevens MW, Schultz T, Scribano PV. Difficulty in obtaining peak expiratory flow measurements in children with acute asthma. Pediatr Emerg Care. 2004 Jan; 20 (1):22-6

3. Sharon R. Smith, Jack D. Baty, Dee Hodge. Validation of the Pulmonary Score: An Asthma Severity Score for Children. Academic emergency medicine February 2002, Volume 9, Number 2

4. Chalut DS, Ducharme FM, Davis GM. The Preschool Respiratory Assessment Measure (PRAM): a responsive index of acute asthma severity. J Pediatr. 2000 Dec; 137 (6): 762-8.

5. Gorelick MH, Stevens MW, Schultz TR, Scribano PV. Performance of a novel clinical score, the Pediatric Asthma Severity Score (PASS), in the evaluation of acute asthma. Acad Emerg Med. 2004 Jan; 11 (1): 10-8.

6. Serge Gouin , Robidas, Gravel, Guimont, Chalut, Devendra A. Prospective Evaluation of Two Clinical Scores for Acute Asthma in Children 18 Months to 7 Years of Age. Academic Emergency Medicine, Volume 17, Issue 6, pages 598-603, June 2010

7. Birken CS, Parkin PC, Macarthur C. Asthma severity scores for pre-schoolers displayed weaknesses in reliability, validity, and responsiveness. J Clin Epidemiol. 2004 Nov; 57 (11): 1177-81.

8. Kerem E, Canny G, Tibshirani R, et al. Clinical physiologic correlations in acute asthma of childhood. Pediatrics.1991; 87:481-6.

9. Yung M, South M, Byrt T. Evaluation of an asthma severity score. J Paediatric Child Health.1996; 32:261-4.

\section{AUTHORS:}

1. Chandrakala P.

2. A. C. Ramesh

3. Chaitra Rao B.

\section{PARTICULARS OF CONTRIBUTORS:}

1. Associate Professor, Department of Paediatrics, Kempegowda Institute of Medical Sciences and Research Centre.

2. Professor, Department of Paediatrics, Kempegowda Institute of Medical Sciences and Research Centre.

3. Post Graduate, Department of Paediatrics, Kempegowda Institute of Medical Sciences and Research Centre.
NAME ADDRESS EMAIL ID OF THE CORRESPONDING AUTHOR:

Dr. Chaitra Rao B, C/o, IKS Sharma, No. 67, South End Road, Near Nagasandra Circle, Basavanagudi, Bangalore - 560004

E-mail: drchaitra.su@gmail.com

Date of Submission: 07/02/2014. Date of Peer Review: 08/02/2014. Date of Acceptance: 18/02/2014. Date of Publishing: 04/03/2014. 